\title{
Overexpression of IncRNA GATA6-AS inhibits cancer cell proliferation in mantle cell lymphoma by downregulating GLUT1
}

\author{
ZHENWEI FAN $^{1}$, XUAN WANG ${ }^{2}$, PENG LI $^{3}$, CHUNLI MEI $^{3}$, MIN ZHANG $^{1}$ and CHUNSHAN ZHAO ${ }^{1}$ \\ ${ }^{1}$ Nursing College of Beihua University; ${ }^{2}$ Department of Hematology, Affiliated Hospital of Beihua University, \\ Jilin City, Jilin 132013; ${ }^{3}$ Department of Oncology, Jilin Central Hospital, Jilin City, Jilin 132000, P.R. China
}

Received August 22, 2018; Accepted April 24, 2019

DOI: $10.3892 / \mathrm{ol} .2019 .10540$

\begin{abstract}
Long non-coding RNA GATA6 antisense RNA 1 (lncRNA GATA6-AS) is a recently identified lncRNA that is involved in endothelial-mesenchymal transition. The present study aimed to investigate the involvement of GATA6-AS in the progression of mantle cell lymphoma (MCL). It was found that plasma lncRNA GATA6-AS expression level was downregulated in patients with MCL, compared with that in healthy controls. Downregulation of IncRNA GATA6-AS has potential diagnostic value in early stage MCL. Overexpression of lncRNA GATA6-AS resulted in inhibited glucose uptake in the human cell lines JVM-2 and Z-138 MCL. Inhibited expression of glucose transporter 1 (GLUT1) was observed in MCL cells following lncRNA GATA6-AS overexpression, whilst GLUT1 overexpression did not alter the expression of lncRNA GATA6-AS. Additionally, lncRNA GATA6-AS overexpression inhibited, whilst GLUT1 overexpression promoted the proliferation of JVM-2 and Z-138 MCL cells; GLUT1 overexpression partially reversed the inhibitory effects of lncRNA GATA6-AS overexpression. It was therefore concluded that IncRNA GATA6-AS may inhibit cancer cell proliferation in MCL by downregulating GLUT1.
\end{abstract}

\section{Introduction}

Tumor growth is the basis for all aspects of cancer development (1); therefore, the inhibition of tumor cell proliferation is considered to be a promising therapeutic strategy for cancer treatment (2). Mantle cell lymphoma (MCL), as a rare subtype of non-Hodgkin lymphoma is associated with poor patient

Correspondence to: Dr Xuan Wang, Department of Hematology, Affiliated Hospital of Beihua University, 12 Jiefang Middle Road, Jilin City, Jilin 132013, P.R. China

E-mail: lwippz2@163.com

Dr Peng Li, Department of Oncology, Jilin Central Hospital, 4 Nanjing Street, Jilin City, Jilin 132000, P.R. China

E-mail: gdvprd8@163.com

Key words: mantle cell lymphoma, glucose transporter 1, long non-coding RNA GATA6 antisense RNA 1, glucose uptake, proliferation prognosis even after active treatment (3). Following great efforts to improve the treatment of MCL, a series of novel drugs have been developed, the uses of which have resulted in markedly improved patient outcomes $(4,5)$. However, the median survival time of patients with MCL remains at 10 years, thus further improvements are required (6).

The reprogramming of glucose metabolism is frequently observed in cancer cells (7), and accelerated glucose metabolism is able to distinguish cancer cells from normal cells (8). The initiation of glucose metabolism requires the uptake of glucose into cells, in which glucose transporter 1 (GLUT1) facilitates the transport of glucose across the mammalian plasma membrane (9). Overexpression of GLUT1 is believed to contribute to the proliferation of cancer cells $(10,11)$. The recently identified long non-coding RNA GATA6 antisense RNA 1 (IncRNA GATA6-AS) plays a pivotal role in endothelial-mesenchymal transition (12). Preliminary microarray data, prior to the present study, identified downregulation of IncRNA GATA6-AS in patients with MCL. In the present study it was revealed that IncRNA GATA6-AS may inhibit cancer cell proliferation in MCL by downregulating GLUT1.

\section{Materials and methods}

Human samples and cell lines. Plasma samples were derived from the blood of 47 patients with MCL (patient group) and 42 healthy volunteers (control group), who were admitted to the Jilin Central Hospital (Jilin, China) between January 2015 and May 2018. All healthy volunteers possessed normal physiological conditions, as determined by systemic physiological examination. The inclusion criteria for patients were as follows: i) Patients with MCL at stage I or II, confirmed by histopathological testing; and ii) patients fully understood the experimental protocol and signed informed content. Exclusion criteria: i) Patients with MCL in addition to another disease/s; and ii) patients who had received treatment up to 3 months before admission. The patient group was composed of 25 males and 22 females, aged between 26 and 67 years (mean age, $46.8 \pm 4.8$ years). The control group was composed of 22 females and 20 males, and aged between 25 and 66 years, (mean age, $45.9 \pm 4.4$ years). Both groups possessed a similar age and gender distribution. The present study was approved by the Ethics committee of Jilin Central Hospital, and all participants gave written informed consent to participate. 
JVM-2 and Z-138 human MCL cell lines were provided by the American Type Culture Collection (ATCC). ATCC-formulated RPMI-1640 medium (ATCC; cat. no. 30-2001) supplemented with $10 \%$ fetal bovine serum (ATCC; cat. no. 30-2020) was used to culture cells under normal conditions $\left(37^{\circ} \mathrm{C} ; 5 \% \mathrm{CO}_{2}\right)$.

Reverse transcription-quantitative polymerase chain reaction $(R T-q P C R)$. The Monarch ${ }^{\circledR}$ Total RNA Miniprep kit (New England BioLabs, Inc.) was used to extract total RNA from cells and patient samples, and the High-Capacity cDNA RT kit (Thermo Fisher Scientific, Inc.) was used to synthesize cDNA (both according to the manufacturer's protocol) using following conditions: $25^{\circ} \mathrm{C}$ for $5 \mathrm{~min}, 55^{\circ} \mathrm{C}$ for $20 \mathrm{~min}$ and $80^{\circ} \mathrm{C}$ for $5 \mathrm{~min}$. The SuperScript III Platinum One-Step RT-qPCR kit (Thermo Fisher Scientific, Inc.) was used to prepare all PCR reactions. The primer sequences were as follows: IncRNA GATA6-AS forward, 5'-ATGCGCTTTTTGCCCTGAAG-3', and reverse, 5'-AGGTCAGCTGGGGAATGTTG-3'; $\beta$-actin forward, 5'-GACCTCTATGCCAACACAGT-3', and reverse, 5'-AGTACTTGCGCTCAGGAGGA-3'. Thermocylcing conditions: $95^{\circ} \mathrm{C}$ for $2 \mathrm{~min}$, followed by 40 cycles of $95^{\circ} \mathrm{C}$ for $15 \mathrm{sec}$ and $56^{\circ} \mathrm{C}$ for $30 \mathrm{sec}$. RNA expression levels were quantified using the $2^{-\Delta \Delta \mathrm{Cq}}$ method (13), and normalized to $\beta$-actin.

Cell transfection. IncRNA GATA6-AS and GLUT1 expression vectors were designed and synthesized by Shanghai GenePharma Co., Ltd. Cells were cultured to 80-90\% confluence and Lipofectamine ${ }^{\circledR} 2000$ reagent (Invitrogen; Thermo Fisher Scientific, Inc.) was used to transfect cancer cells with the appropriate vectors $(15 \mathrm{nM})$. Cells transfected with empty vector were used as the negative control (NC), and untransfected cells were used as the control (C). lncRNA GATA6-AS and GLUT1 expression was detected $12 \mathrm{~h}$ post-transfection. The overexpression rates of IncRNA GATA6-AS and GLUT1 reached $180 \%$ (180-200\%) prior to subsequent experimentation.

Glucose uptake assay. Following transfection, cells were harvested and counted. Subsequently, $3 \times 10^{5}$ cells were washed with PBS and resuspended in $2 \mathrm{ml}$ Krebs-Ringer-HEPES (KRH) buffer, which was composed of $25 \mathrm{mM}$ HEPES (pH 7.4), $120 \mathrm{mM} \mathrm{NaCl}, 1.3 \mathrm{mM} \mathrm{CaCl}_{2}, 1.2 \mathrm{mM} \mathrm{MgSO}_{4}$, $1.3 \mathrm{mM} \mathrm{KH}_{2} \mathrm{PO}_{4}$ and $5 \mathrm{mM} \mathrm{KCl}$. To initiate glucose uptake, $1 \mu \mathrm{Ci}$ of [3H]-2-deoxyglucose (PerkinElmer, Inc.) was added and cells were cultured at $37^{\circ} \mathrm{C}$ for $30 \mathrm{~min}$. Cells were then washed in ice-cold KRH buffer to terminate glucose uptake. Liquid scintillation spectrometry was used to measure radioactivity, and the $[3 \mathrm{H}]$-2-deoxyglucose content of the cells was expressed as disintegrations per minute.

In vitro cell proliferation assay. Following transfection, the Cell Counting Kit-8 (CCK-8; Sigma-Aldrich; Merck KGaA) assay was used to assess cell proliferation ability. Briefly, cells were harvested to prepare a single cell suspension $\left(3 \times 10^{4}\right.$ cells $\left./ \mathrm{ml}\right)$, which was transferred to a 96 -well plate (100 $\mu \mathrm{l} /$ well). Cells were incubated at $37^{\circ} \mathrm{C}, 5 \% \mathrm{CO}_{2}$, and $\mathrm{CCK}-8$ solution was added at 24, 48, 72 and 96-h time points. Optical density values were determined using the Fisherbrand ${ }^{\mathrm{TM}}$ accuSkan $^{\mathrm{TM}}$ GO UV/Vis Microplate Spectrophotometer (Thermo Fisher Scientific, Inc.) at $450 \mathrm{~nm}$.
Western blot analysis. Western blotting was performed using conventional methods. RIPA solution (Sangon Biotech Co., Ltd.,) was used to extract the total protein from cells, and the protein concentrations were determined using a bicinchoninic acid assay kit (Sangon Biotech Co., Ltd.). Electrophoresis was performed using $10 \%$ SDS-PAGE gels with $35 \mu \mathrm{g}$ protein per lane. Following gel transfer to PVDF membranes, blocking was performed using PBS containing 5\% non-fat milk at room temperature for $2 \mathrm{~h}$. Primary, rabbit anti-human antibodies for GLUT1 (1:1,200; cat. no. ab15309) and GAPDH (1:2,000; cat. no. ab8245) were purchased from Abcam, and incubated with the membranes at $4^{\circ} \mathrm{C}$ for $12 \mathrm{~h}$. A secondary, goat anti-rabbit IgG-HRP antibody (1:1,000; cat. no. MBS435036) was purchased from MyBioSource, Inc., and incubation was performed at room temperature for $2 \mathrm{~h}$. Signal development was performed using ECL ${ }^{\mathrm{TM}}$ Select Western Blotting Detection Reagent (Sigma-Aldrich; Merck KGaA) and ImageJ v1.46 software (National Institutes of Health) was used to capture gel images.

Statistical analysis. The data were processed using GraphPad prism 6 (GraphPad Software, Inc.). All experiments were performed in triplicate and the data are presented as the mean \pm standard deviation. Student's t-test was used for comparisons between two groups, and one-way ANOVA followed by Tukey's test was used for comparisons among multiple groups. Receiver operating characteristic (ROC) curve analysis was performed to evaluate the diagnostic value of plasma lncRNA GATA6-AS in MCL, with MCL patients as true positive cases, and healthy volunteers as true negative cases. $\mathrm{P}<0.05$ was considered to indicate a statistically significant difference.

\section{Results}

Downregulation of IncRNA GATA6-AS distinguishes MCL patients from healthy controls. RT-qPCR was performed to detect the expression of IncRNA GATA6-AS in the plasma of patients with MCL and healthy controls. Compared with the healthy controls, plasma expression levels of lncRNA GATA6-AS were significantly reduced in patients with MCL $(\mathrm{P}<0.05$; Fig. 1A). ROC curve analysis was performed to evaluate the diagnostic value of plasma lncRNA GATA6-AS in MCL. As revealed in Fig. 2B, the area under the curve was 0.9195 , with a standard error of 0.02916 and $95 \%$ confidence interval of 0.8623-0.9767.

IncRNA GATA6-AS overexpression inhibits glucose uptake in JVM-2 and Z-138 human MCL cells. Glucose uptake in JVM-2 and Z-138 human MCL cells was detected using a glucose uptake assay. Compared with the control and negative control groups, glucose uptake was significantly reduced in JVM-2 (Fig. 2A) and Z-138 (Fig. 2B) human MCL cells following lncRNA GATA6-AS overexpression $(\mathrm{P}<0.05)$.

IncRNA GATA6-AS regulates GLUT1 expression in JVM-2 and Z-138 human MCL cells. GLUT1 is a one of the principal components of glucose uptake. Therefore, the expression of GLUT1 was detected in JVM-2 and Z-138 human MCL cell lines following IncRNA GATA6-AS overexpression. 
A

$$
\text { A }
$$

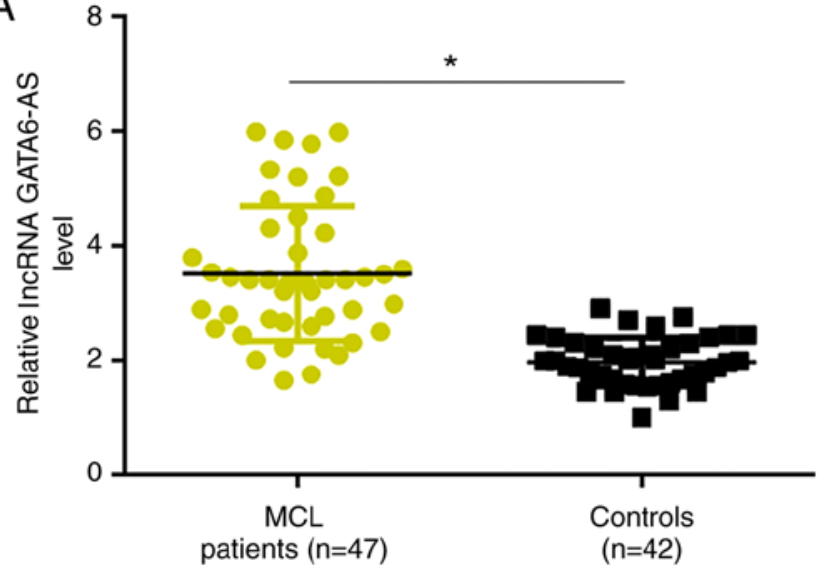

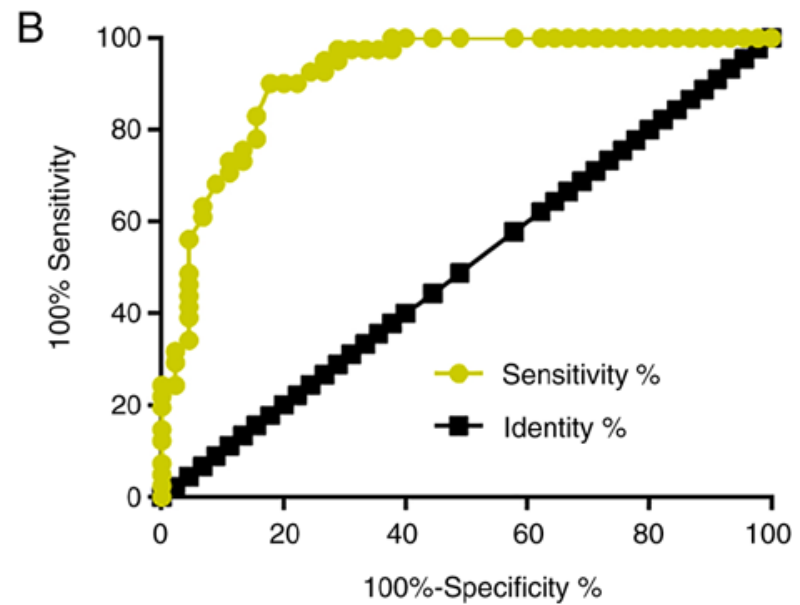

Figure 1. Downregulation of lncRNA GATA6-AS distinguishes patients with MCL from healthy controls. (A) Compared with healthy controls, plasma expression levels of lncRNA GATA6-AS were significantly reduced in patients with MCL. (B) Downregulation of lncRNA GATA6-AS distinguished patients with MCL from healthy controls. "P<0.05. IncRNA GATA6-AS, long non-coding RNA GATA6 antisense RNA 1; MCL, mantle cell lymphoma.
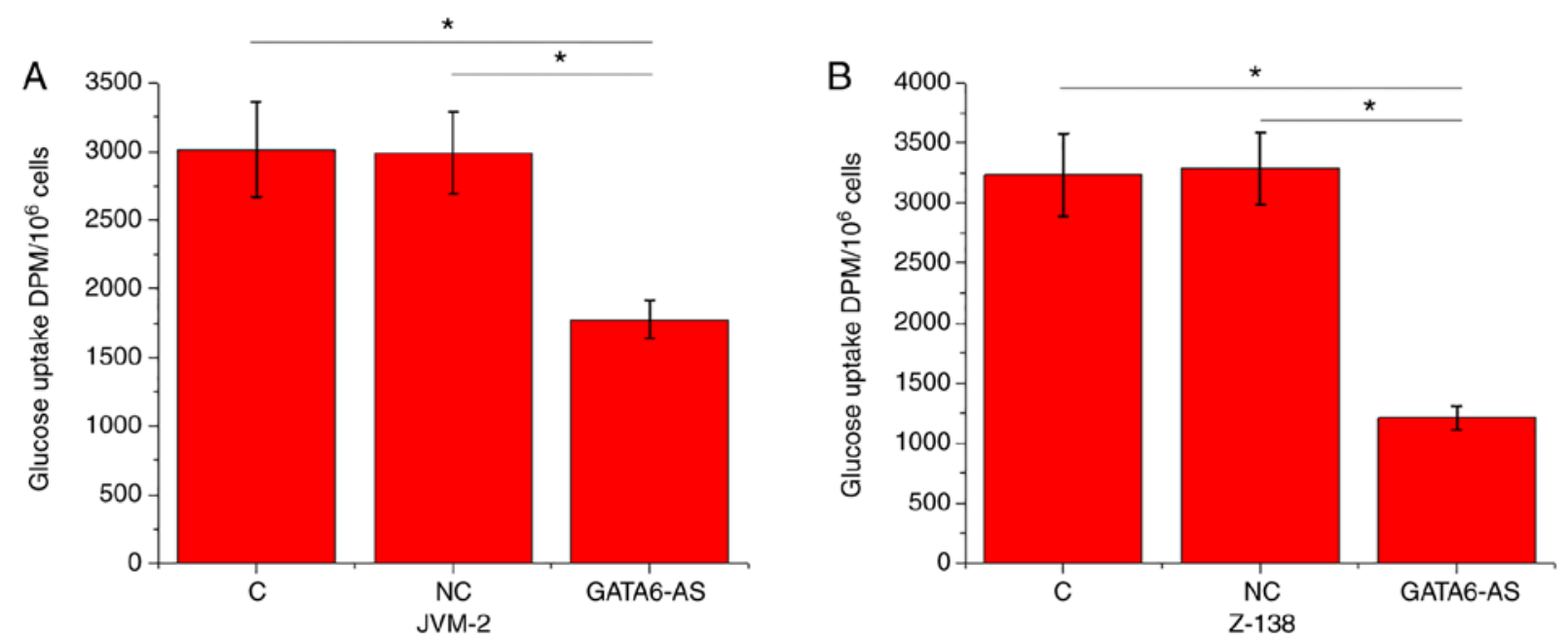

Figure 2. IncRNA GATA6-AS overexpression inhibits glucose uptake in JVM-2 and Z-138 human MCL cells. IncRNA GATA6-AS overexpression resulted in significantly inhibited glucose uptake in (A) JVM-2 and (B) Z-138 human MCL cell lines. "P<0.05. IncRNA GATA6-AS, long non-coding RNA GATA6 antisense RNA 1; MCL, mantle cell lymphoma; C, control; NC, negative control; DPM, disintegrations per minute.

Compared with control and negative control groups, expression of GLUT1 was significantly reduced in both cell lines following IncRNA GATA6-AS overexpression $(\mathrm{P}<0.05$; Fig. 3A). By contrast, no significant differences in the expression levels of IncRNA GATA6-AS were observed following GLUT1 overexpression ( $\mathrm{P}<0.05$; Fig. 3B).

IncRNA GATA6-AS regulates GLUT1 involvement in the proliferation of JVM-2 and Z-138 human MCL cells. Following transfection with IncRNA GATA6-AS and GLUT1 expression vectors, the proliferation of JVM-2 and Z-138 human MCL cells was detected using a CCK-8 assay. Compared with control and negative control groups, GATA6-AS overexpression significantly inhibited, while GLUT1 overexpression significantly promoted the proliferation of JVM-2 (Fig. 4A) and Z-138 (Fig. 4B) human MCL cells. Compared with cells transfected with GATA6-AS expression vectors alone, cells transfected with both GATA6-AS and GLUT1 expression vectors showed significantly increased proliferation rates $(\mathrm{P}<0.05)$.

\section{Discussion}

IncRNA GATA6-AS has recently been identified as a key component in endothelial-mesenchymal transition, while its involvement in other physiological or pathological processes is unknown. In the present study, a novel function of lncRNA GATA6-AS was reported in MCL. This is the first report to indicate the involvement of lncRNA GATA6-AS in cancer cell proliferation, which is likely to be as a result of its interaction with GLUT1.

As a primary component of glucose uptake, GLUT1 is involved in the regulation of cancer cell proliferation in different types of human malignancies, including prostate cancer (10) and triple-negative breast cancer (11). The involvement of GLUT1 in MCL still hasn't been well studied. In the present study, GLUT1 overexpression resulted in significant promotion of MCL cell proliferation. Therefore, GLUT1 may also serve an oncogenic role in MCL by promoting cancer cell proliferation. 
A
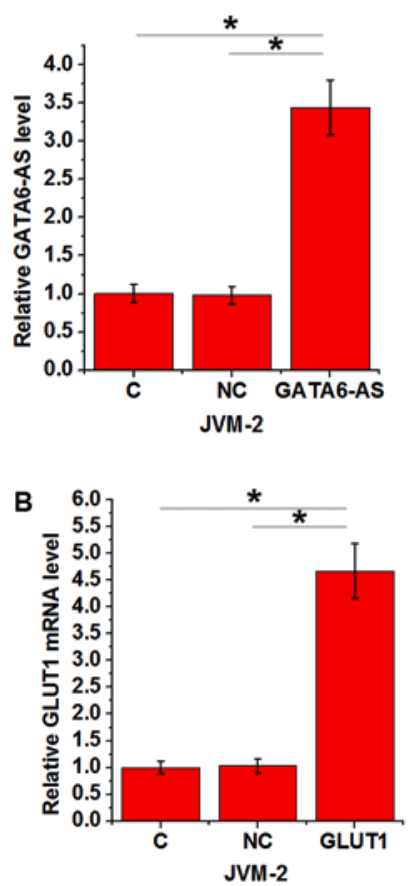

JVM-2

C NC GATA6-AS
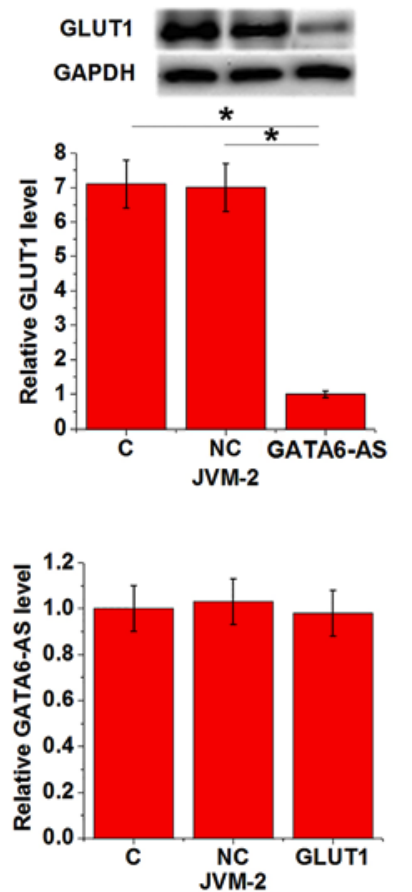
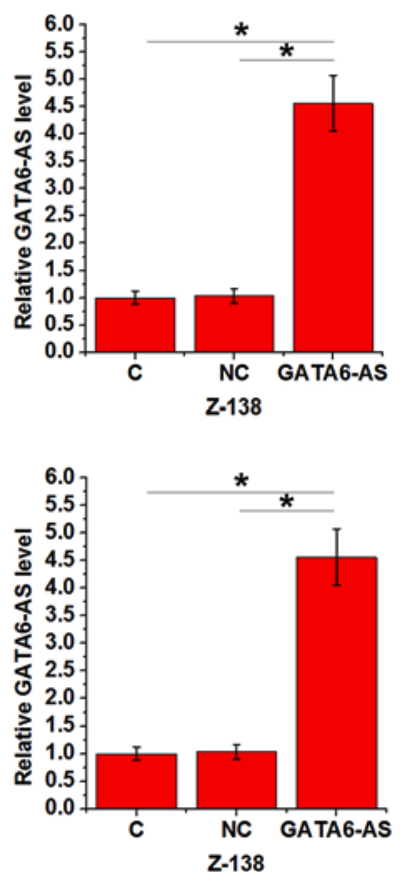

Z-138

C NC GATA6-AS
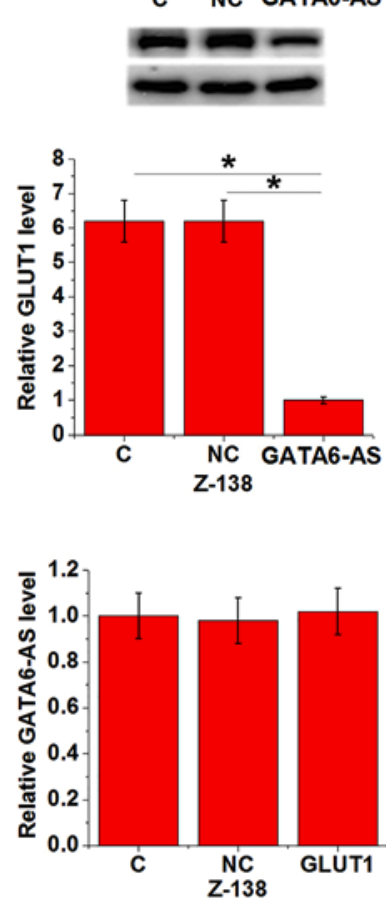

Figure 3. IncRNA GATA6-AS regulates GLUT1 expression in JVM-2 and Z-138 human MCL cells. (A) lncRNA GATA6-AS overexpression led to significantly inhibited expression of GLUT1 in JVM-2 and Z-138 human MCL cell lines, while (B) GLUT1 overexpression had no significant effects on lncRNA GATA6-AS expression in either cell line. ${ }^{*} \mathrm{P}<0.05$. long non-coding RNA GATA6 antisense RNA 1; GLUT1, glucose transporter 1; MCL, mantle cell lymphoma; C, control; NC, negative control.
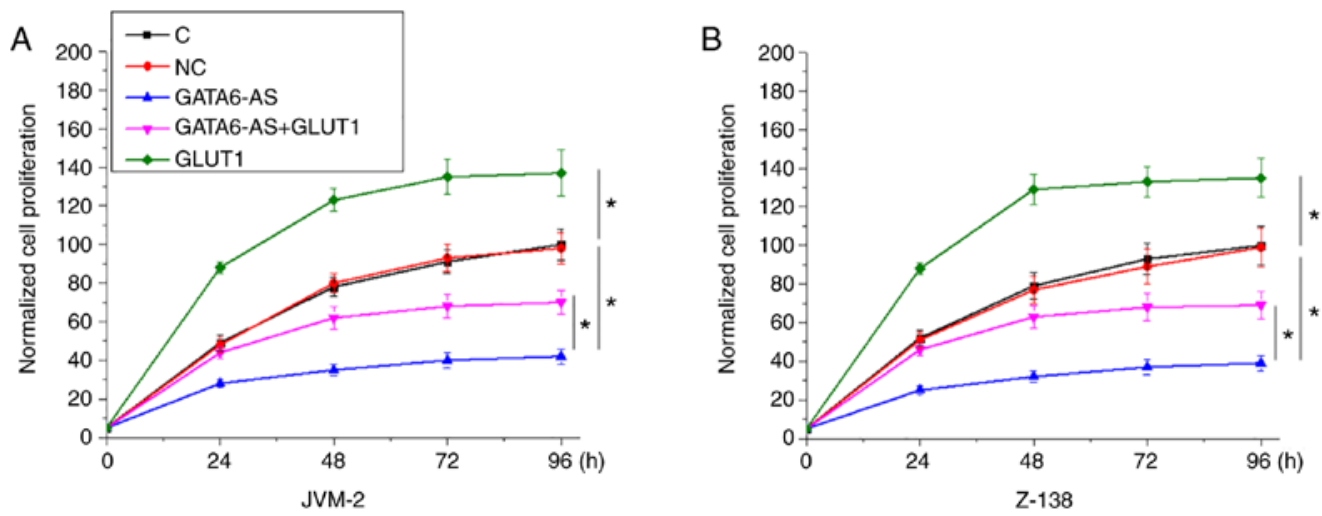

Figure 4. IncRNA GATA6-AS regulates GLUT1 in the proliferation of JVM-2 and Z-138 human MCL cells. GATA6-AS overexpression significantly inhibited, whilst GLUT1 overexpression significantly promoted the proliferation of cells of (A) JVM-2 and (B) Z-138 human MCL cell lines. GLUT1 overexpression partially reversed the inhibitory effects of GATA6-AS overexpression on cell proliferation. "P<0.05. long non-coding RNA GATA6 antisense RNA 1; GLUT1, glucose transporter 1; MCL, mantle cell lymphoma; C, control; NC, negative control.

It has been reported that the development of MCL is accompanied by changes in the expression pattern of a large set of lncRNAs (14). However, the number of studies addressing the functions of these IncRNAs in MCL is limited (15). The findings of the present study indicate that the inhibition of IncRNA GATA6-AS expression may serve as a potential therapeutic target for the treatment of MCL. It was also observed that IncRNA GATA6-AS was downregulated in MCL, and that IncRNA GATA6-AS overexpression inhibited the proliferation of MCL cell lines. This suggests that in MCL, GATA6-AS is likely to be a tumor suppressor lncRNA, and that its overexpression may be used therapeutically.
Early diagnosis is the key to successful post-treatment survival in patients with cancer (16). The present study only included patients in the early cancer stages of MCL (stage I and II). ROC curve analysis revealed that downregulation of lncRNA GATA6-AS effectively distinguished between patients and healthy controls. Therefore, IncRNA GATA6-AS may have potential in the early diagnosis of MCL.

GLUT1 is involved in cancer development and progression through its interaction with different signaling molecules, including lncRNAs $(17,18)$. The present study revealed that this involvement is likely to be downstream of IncRNA GATA6-AS in the regulation of MCL cell proliferation. However, as GLUT1 
overexpression only attenuated, not reversed the inhibitory effects of GATA6-AS overexpression on cell proliferation, IncRNA GATA6-AS may interact with multiple signaling molecules. Future studies will focus on the identification of other downstream effectors of IncRNA GATA6-AS.

Notably, GLUT 2-4 (class 1 GLUT), GLUT5 (class 2 GLUT) and GLUT6 (class 3 GLUT) failed to respond to IncRNA GATA6-AS overexpression (preliminary data not shown), indicating a specific interaction between GLUT1 and lncRNA GATA6-AS. In addition, no potential targeting site of 1ncRNA GATA6 was identified on GLUT1; therefore, it was hypothesized that the interactions between lncRNA GATA6 and GLUT1 were mediated by other means, including pathological factors. Future studies aim to detect the levels of glycolytic intermediates to confirm the involvement of GLUT1 in MLC. Furthermore, the interaction between GATA6AS with GATA6S in MCL is also a topic for future investigation.

In conclusion, IncRNA GATA6-AS was downregulated in MCL. Its overexpression may serve as a potential therapeutic strategy for the treatment of MCL, by inhibiting cancer cell proliferation through the downregulation of GLUT1.

\section{Acknowledgements}

Not applicable.

\section{Funding}

The present study was supported by the Jilin Provincial Health Department in China (grant no. 2017ZC029), and the Science and Technology Bureau project of Jilin City (grant no. 201830557).

\section{Availability of data and materials}

The datasets used and/or analyzed during the present study are available from the corresponding author upon reasonable request.

\section{Authors' contributions}

$\mathrm{XW}$ and PL designed the experiments. ZF performed the experiments with the assistance of $\mathrm{CM}, \mathrm{MZ}$ and $\mathrm{CZ}$, who also analyzed the data. ZF, XW and PL wrote the manuscript, which was revised by all of the authors.

\section{Ethics approval and consent to participate}

The present study was approved by the Ethics Committee of Jilin Central Hospital, and all participants gave written informed consent to participate.

\section{Patient consent for publication}

Not applicable.

\section{Competing interests}

The authors declare that they have no competing interests.

\section{References}

1. Chang DW, Satterfield WC, Son D, Neto N, Madewell JE, Raymond AK, Patrick CW Jr, Miller MJ, Costelloe CM and Weber KL: Use of vascularized periosteum or bone to improve healing of segmental allografts after tumor resection: An ovine rib model. Plast Reconstr Surg 123: 71-78, 2009.

2. Sulciner ML, Serhan CN, Gilligan MM, Mudge DK, Chang J, Gartung A, Lehner KA, Bielenberg DR, Schmidt B, Dalli J, et al: Resolvins suppress tumor growth and enhance cancer therapy. J Exp Med 215: 115-140, 2018.

3. Cheah CY, Seymour JF and Wang ML: Mantle cell lymphoma. J Clin Oncol 34: 1256-1269, 2016.

4. Robak T, Huang H, Jin J, Zhu J, Liu T, Samoilova O, Pylypenko H, Verhoef G, Siritanaratkul N, Osmanov E, et al: Bortezomib-based therapy for newly diagnosed mantle-cell lymphoma. N Engl J Med 372: 944-953, 2015.

5. Ruan J, Martin P, Shah B, Schuster SJ, Smith SM, Furman RR, Christos P, Rodriguez A, Svoboda J, Lewis J, et al: Lenalidomide plus rituximab as initial treatment for mantle-cell lymphoma. N Engl J Med 373: 1835-1844, 2015.

6. Eskelund CW, Kolstad A, Jerkeman M, Räty R, Laurell A, Eloranta S, Smedby KE, Husby S, Pedersen LB, Andersen NS, et al: 15-year follow-up of the second nordic mantle cell lymphoma trial (MCL2): Prolonged remissions without survival plateau. Br J Haematol 175: 410-418, 2016.

7. Hay N: Reprogramming glucose metabolism in cancer: Can it be exploited for cancer therapy? Nat Rev Cancer 16: 635-649, 2016.

8. Liberti MV and Locasale JW: The warburg effect: How does it benefit cancer cells? Trends Biochem Sci 41: 211-218, 2016.

9. Olson AL and Pessin JE: Structure, function, and regulation of the mammalian facilitative glucose transporter gene family. Annu Rev Nutr 16: 235-256, 1996.

10. Xiao H, Wang J, Yan W, Cui Y, Chen Z, Gao X, Wen X and Chen J: GLUT1 regulates cell glycolysis and proliferation in prostate cancer. Prostate 78: 86-94, 2018.

11. Oh S, Kim H, Nam K and Shin I: Glut1 promotes cell proliferation, migration and invasion by regulating epidermal growth factor receptor and integrin signaling in triple-negative breast cancer cells. BMB Rep 50: 132-137, 2017.

12. Neumann P, Jaé N, Knau A, Glaser SF, Fouani Y, Rossbach O, Krüger M, John D, Bindereif A, Grote P, et al: The lncRNA GATA6-AS epigenetically regulates endothelial gene expression via interaction with LOXL2. Nat Commun 9: 237, 2018.

13. Livak KJ and Schmittgen TD: Analysis of relative gene expression data using real-time quantitative PCR and the 2(-Delta Delta C(T)) method. Methods 25: 402-408, 2001.

14. Hu G, Gupta SK, Troska TP, Nair A and Gupta M: Long non-coding RNA profile in mantle cell lymphoma identifies a functional lncRNA ROR1-AS1 associated with EZH2/PRC2 complex. Oncotarget 8: 80223-80234, 2017.

15. Wang X, Sehgal L, Jain N, Khashab T, Mathur R and Samaniego F: LncRNA MALAT1 promotes development of mantle cell lymphoma by associating with EZH2. J Transl Med 14: 346, 2016

16. Vose JM: Mantle cell lymphoma: 2015 update on diagnosis, risk-stratification, and clinical management. Am J Hematol 90: 739-745, 2015.

17. Zou ZW, Ma C, Medoro L, Chen L, Wang B, Gupta R, Liu T, Yang XZ, Chen TT, Wang RZ, et al: LncRNA ANRIL is up-regulated in nasopharyngeal carcinoma and promotes the cancer progression via increasing proliferation, reprograming cell glucose metabolism and inducing side-population stem-like cancer cells. Oncotarget 7: 61741-61754, 2016.

18. Liu X and Gan B: IncRNA NBR 2 modulates cancer cell sensitivity to phenformin through GLUT1. Cell Cycle 15: 3471-3481, 2016. International (CC BY-NC-ND 4.0) License. 